\title{
Diversidade de Gênero nos Conselhos Administrativos e sua Relação com Desempenho e Risco Financeiro nas Empresas Familiares
}

\section{Gender Diversity in Board of Directors and the Relationship between Performance and Financial Risk in Family Firms}

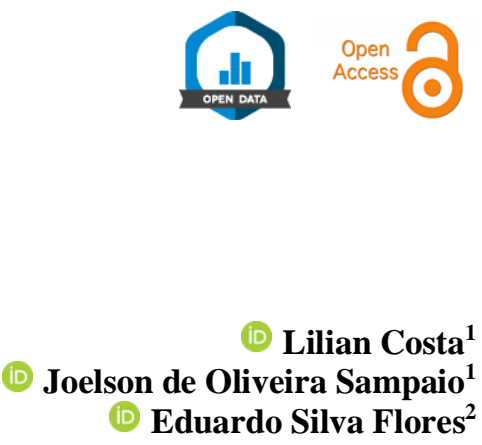

Fundação Getulio Vargas, Escola de Economia de São Paulo, São Paulo, SP, Brasil ${ }^{1}$ Universidade de São Paulo, Faculdade de Economia, Administração e Contabilidade, São Paulo, SP, Brasil²

Editores convidados para este artigo: Aureliano Angel Bressan (D) Eduardo Schiehll (iD) Jairo Laser Procianoy Luiz Ricardo Kabbach de Castro (D)
Artigo recebido em 15.12.2018

Última versão recebida em 12.08.2019

Aprovado em 30.08.2019

Editor-chefe: Wesley Mendes-Da-Silva (i)

\# de revisores convidados até a decisão

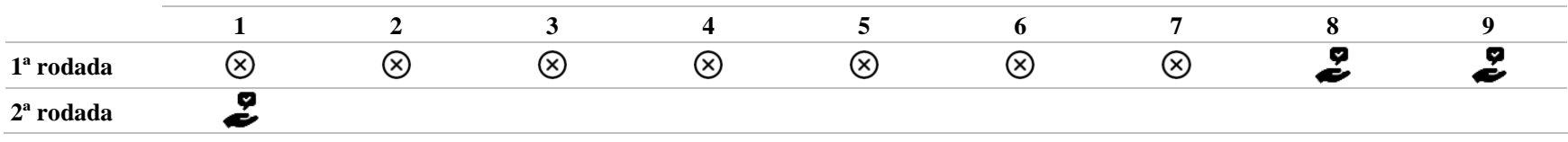




\title{
Resumo
}

Este trabalho analisa a influência da participação feminina sobre o desempenho e risco financeiro das empresas, considerando uma amostra composta por 218 empresas, listadas e negociadas na B3 (Bovespa), nos períodos de 2010 a 2016. O estudo analisa também a influência da participação feminina em empresas de controle familiar. Utilizando painel com efeitos aleatórios e as variáveis dummy de controle familiar e percentual de presença feminina no conselho de administração, o estudo procurou analisar como essas variáveis e suas interações podem afetar o desempenho financeiro das empresas. Embora a representatividade feminina tenha crescido mais de 50\% nos últimos anos, tal participação, no entanto, no conselho de administração das empresas brasileiras ainda é minoritária, próxima de $9 \%$ do total pesquisado. A estrutura de propriedade em mãos familiares é bastante relevante, com a percentagem de 63\%. Os resultados sugerem uma relação positiva da participação feminina e a variável Q de Tobin, utilizada como proxy para geração de valor, porém essa relação é mais fraca nas empresas familiares. Outro resultado encontrado é que a volatilidade, aqui tomada como proxy de risco, é reduzida em empresas de controle familiar.

Palavras-chave: empresas com controle familiar, diversidade de gênero, desempenho financeiro, risco, conselhos de administração.

\begin{abstract}
This paper analyzes the influence of female participation on the performance and financial risk considering a sample of 218 public companies traded on B3 (Bovespa) from 2010 a 2016. The study also analyzes the influence of female participation on family control companies. Using a random effects methodology and family control dummy and percentage of female presence in boards of director, the study sought to analyze how theses variables and their interactions affect the financial performance of companies. Although the female representation has grown more than 50\% in recent years, this share, however, in the board of directors of Brazilian companies is still a minority, close to $9 \%$ of the total surveyed. The ownership structure in the family firms is very relevant, with the percentage of $63 \%$. The results suggest a positive relation between female participation and the Tobin-Q, used by value's proxy, however, this relationship is weaker for firms with a family control. Another result found is that volatility, taken here as a risk's proxy, is reduced in family run-business.
\end{abstract}

Keywords: firms with family control, gender diversity, financial performance, risk, board of directors.

JEL Code: G3, J16, N26.

RAC, Maringá, v. 23, n. 6, SI Corp Gov Fam Bus, art. 3, pp. 721-738, novembro/dezembro, 2019, http://rac.anpad.org.br, (cc) E` 


\section{Introdução}

Com a presença da mulher no mercado de trabalho e nas universidades era de se esperar que sua participação também atingisse os cargos diretivos das empresas. Diversidade de gênero tem se tornado um assunto relevante às empresas e aos formulares de políticas públicas. As propostas de aumento da participação feminina nas diretorias são baseadas no racional lógico-dedutivo. Tal fato é benéfico para a governança corporativa, e resulta em um aumento do desempenho financeiro das organizações (Bruni, Gherardi, \& Poggio, 2004). Adicionalmente, tais propostas informam os custos e benefícios desta presença.

Uma característica muito comum nas empresas brasileiras é o controle familiar. Isso deve-se, em partes, pelo fato das famílias e o Estado darem origem às atividades econômicas. Para Vidigal (1996), com exceção das empresas criadas pelo governo, as demais possuem em sua origem um fundador ou um pequeno grupo de fundadores, que são seus donos. As ações ou cotas destas empresas possivelmente serão herdadas pelos seus filhos e netos. Daspit, Holt, Chrisman e Long (2016) ressaltam que o evento de sucessão em empresas familiares, é também um evento de caráter social, tendo em vista que se trata de uma perspectiva de troca geracional dos postos de comandos de organizações consolidadas.

Sociedades empresariais e empresas familiares são a base de sustentação da economia brasileira, estas empresas extraem uma força de suas histórias, da identidade e da cultura das famílias (Macêdo, 2001). Dessa forma, a empresa familiar mescla pessoas com determinação, autoconfiança e desejo de trabalhar mais tempo e com mais afinco (Grzybovski, Boscarin, \& Migott, 2002).

Nesse contexto, o presente estudo procurar avaliar se empresas, com maior diversidade de gênero em seus conselhos de administração, possuem indicações de resultados econômico-financeiros superiores ao caso contrário, bem como, se tal advento também se reflete na gestão de riscos dessas organizações no contexto de empresas familiares. Há poucos estudos empíricos no Brasil que analisam o impacto da representatividade feminina nos conselhos de administração vis-à-vis o desempenho financeiro das empresas familiares.

Esse estudo também procura aferir se em empresas com controle familiar há maior participação do gênero feminino nas posições de conselho, sob o suporte dos argumentos estabelecidos por Daspit et al. (2016) e Kabbach de Castro, Aguilera e Crespi (2017), de que a sucessão das posições chave nas organizações de controle familiar ocorre por meio dos herdeiros dos fundadores ou proprietárias dessas companhias. Portanto, pode-se esperar que em tais empresas encontre maior representatividade de mulheres nas cadeiras dos CAs.

Esse estudo emprega uma amostra de empresas negociadas na B3 (Bovespa) no período de 2010 até 2016. A literatura internacional sobre o tema é abrangente, já no Brasil, ela é pouco explorada. Essa pesquisa, por exemplo, teve como referência teórica nacional os autores Silva e Martins (2015) e Nisiyama (2016) e os autores internacionais Sila, Gonzales e Hagendorff (2016) e Adams e Ferreira (2009).

Este estudo contribui com os seguintes aspectos: (a) apresenta uma análise descritiva das empresas com controle familiar e a participação do gênero feminino nos conselhos de administração; (b) relaciona diversidade de gênero na composição do conselho de administração com o desempenho financeiro das empresas de controle familiar, apresentando evidência empírica para esta relação; (c) relaciona também a participação feminina no conselho de administração com o risco financeiro, procurando entender se essa relação ocorre de maneira distinta nas empresas de controle familiar.

A preocupação com a diversidade de gênero na composição do conselho de administração chegou ao Congresso Nacional através do Projeto de Lei do Senado no 112 (2010), que recomenda a proporção mínima de participantes, de acordo com o exemplo de outros países, que aprovaram legislação e/ou instrumento normativo para a presença feminina no conselho de administração. Tal fato pode-se ser observado na Tabela 1. 
Tabela 1

Países com Maior Participação de Mulheres em Conselhos de Administração

\begin{tabular}{clc}
\hline Posição & \multicolumn{1}{c}{ País } & Total \\
\hline $1^{\circ}$ & Noruega & $40,5 \%$ \\
$2^{\circ}$ & Suécia & $27,5 \%$ \\
$3^{\circ}$ & Finlândia & $26,8 \%$ \\
$4^{\circ}$ & Reino Unido & $20,7 \%$ \\
$5^{\circ}$ & França & $18,3 \%$ \\
$6^{\circ}$ & Dinamarca & $17,2 \%$ \\
$7^{\circ}$ & África do Sul & $17,1 \%$ \\
$8^{\circ}$ & Holanda & $17,0 \%$ \\
$9^{\circ}$ & Estados Unidos & $16,9 \%$ \\
$10^{\circ}$ & Israel & $16,6 \%$ \\
\hline
\end{tabular}

Nota. Fonte: Instituto Brasileiro de Governança Corporativa. (2016). Perfil dos Conselhos de Administração (p. 18). Recuperado de https://conhecimento.ibgc.org.br/Lists/Publicacoes/Attachments/23491/Pesquisa_Perfil_Conselhos_2016.pdf

Não há, no entanto, uma avaliação clara na literatura brasileira se em empresas familiares também se repete a mesma tendência de uma representação majoritária de homens nos conselhos. Da amostra pesquisada por esse trabalho, 138 (63\%) das empresas são de controle familiar. Essas empresas são responsáveis por geração de empregos e sustentação da economia (Macêdo, 2001).

As consequências econômico-financeiras de um aumento no número de mulheres no conselho administrativo (CA) de empresas familiares ou não familiares também são pouco compreendidas e pouco analisadas, principalmente no Brasil. Enquanto os estudos das áreas de economia e psicologia constatam que as mulheres assumem menos risco do que os homens, não está claro se uma proporção maior de mulheres nos CAs significa que a empresa possa tomar decisões menos arriscadas e, consequentemente, obter resultados em valores absolutos menores (Barber \& Odean, 2001; Bruni et al., 2004).

Nos CAs, a participação feminina leva a maiores expectativas em relação ao seu papel de supervisionar riscos. Um conselho de administração heterogêneo com a participação feminina pode, portanto, se constituir em uma ferramenta relevante para uma supervisão de risco eficaz (Sila, Gonzalez, \& Hagendorff, 2016).

Adams e Ferreira (2007) estabelecem, também, que desempenho financeiro e risco são questões desafiadoras e possuem uma relação com diversidade de gênero. As características do conselho não são variáveis, aleatórias e exógenas, mas sim um conjunto de escolhas das empresas para se adequarem ao seu ambiente operacional e contratual (Jaskiewicz \& Klein, 2007).

Esse trabalho se organiza em: apresentação das principais plataformas teóricas utilizadas por formulação das hipóteses levantadas; delineamento dos procedimentos metodológicos empregados para consecução desse estudo; apresentação e discussão dos principais resultados obtidos no decorrer do trabalho; limitações de pesquisa; e considerações finais e indicações de futuras pesquisas correlatas ao tema. 


\section{Motivação e Levantamento de Hipóteses}

\section{Conselhos de administração e governança corporativa}

Há diversos estudos relacionados à diversidade de gênero tanto na academia quanto no meio corporativo (Nisiyama, 2016). Esse debate figura como elemento importante para ampliar a heterogeneidade nos conselhos de administração. Refere-se a um tema da governança corporativa contemporânea, cuja discussão tem sido realizada na maioria dos países sob os mais variados aspectos, como experiência profissional, formação acadêmica, gênero, nacionalidade, etnia e idade (Instituto Brasileiro de Governança Corporativa [IBGC], 2016).

O conceito Governança Corporativa envolve aspectos de direção, monitoramento, incentivo e relacionamento entre todos os intervenientes internos e externos a essas organizações (IBGC, 2015). O propósito da governança é conduzir e controlar as atividades de uma organização, pelo estabelecimento de estruturas, regras e procedimentos para tomada de decisões (IBGC, 2015). Essa temática é entendida como o conjunto de mecanismos de incentivo e controle, internos e externos, com o objetivo de minimizar os custos decorrentes do problema de agência (Jensen \& Meckling, 1976; Silveira, 2004).

Os pilares de governança corporativa são: Transparência; Equidade; Prestação de Contas e Responsabilidade Corporativa (IBGC, 2015). Em busca de atender a tais pilares, as empresas se utilizam de diferentes mecanismos como, por exemplo: o conselho de administração, comitês específicos, controles internos, dentre outras ferramentas que perfazem a malha de um sistema de governança corporativa (Álvares, Giocometti, \& Gusso, 2008).

O conselho de administração é uma das principais áreas de Governança Corporativa. Segundo o IBGC (2015), o conselho de administração é um órgão colegiado cujas obrigações residem no direcionamento estratégico de uma organização. Sendo assim, o CA é importante dentro da estrutura corporativa. Ele desempenha o elo entre os acionistas e os executivos com o objetivo de monitorar as decisões gerenciais, com responsabilidade pela formação do quadro de diretores, além de recompensá-los por seus resultados (Monks \& Minow, 2011). O conselho constituído por muitos membros faz com que o conluio entre os tomadores de decisão da alta administração e os agentes de controle seja mais difícil, por isso ele é o mecanismo que permite a separação da gestão e do controle das decisões (Fama \& Jensen, 1983).

Ao lidar com o tema composição dos CAs, o Código das Melhores Práticas de Governança Corporativa traz inovações sobre a diversidade de perfis e permite às empresas os benefícios de argumentos para melhor tomada de decisão (IBGC, 2016).

Entre as novas recomendações do Código, ressaltam-se os aspectos comportamentais dos conselheiros e divulgação de políticas que proporcionem igualdade de oportunidades para que as mulheres possam atingir posições de alta liderança nas organizações (IBGC, 2016).

Ferreira, Cunha e Almeida-Santos (2015) citam os benefícios e custos da diversidade que precisam ser considerados para a composição do CA. Os benefícios são: criatividade e diferentes perspectivas; acesso a recursos e conexões; incentivos para desenvolvimento de carreiras por meio de sinalização e aconselhamento; e, relações públicas, relações com investidores e legitimação. Os mesmos autores indicam que a diversidade na composição do conselho pode trazer consequências, como: conflitos; falta de cooperação; comunicação insuficiente; conselheiros com pouca experiência; qualificações inadequadas; e conflitos de interesses e imposição de agenda.

\section{Caracterização das Empresas Familiares}

As empresas familiares são caracterizadas por uma organização peculiar e extraem uma força especial da história, da identidade e da cultura das famílias que as criaram (Gersick, Davis, Hampton, \& Lansberg, 2006; 
Steinberg \& Blumenthal, 2011). Ela, uma vez constituída, preocupa-se em garantir o sucesso e a perpetuidade do negócio. A principal preocupação das famílias está ligada com quem vai suceder o patriarca para garantir a continuidade da empresa.

Naldi, Chirico, Kellermanns e Camponiano (2015) afirmam que as empresas familiares são organizações carregadas emocionalmente por intensas interações, tanto profissionais como pessoais, entre os membros da família. O apego emocional e o julgamento racional estão entrelaçados e afetam, assim, as tomadas de decisões e os processos operacionais. Gersick, Davis, Hampton e Lansberg (2006) enfatizam que participar de uma empresa familiar é complexo e afeta a todos, pois os papéis são diferentes, como exemplo: quando se exerce o papel de CEO e se tem como vice-presidente, na porta ao lado, a irmã mais nova, ou, ainda, quando se é sócio do cônjuge ou do filho.

Steinberg e Blumenthal (2011) explicam que nesse tipo de empresa pode ocorrer sobreposição de dois sistemas distintos: a família e os negócios. Em decorrência disso, a grande maioria das empresas familiares fracassa devido à falta de alinhamento entre os interesses da família e do negócio.

Gersick et al. (2006) destacam que os maiores dilemas enfrentados pelas empresas familiares são causados pela passagem do tempo, e envolvem mudanças na organização, na família e na distribuição de propriedade, como exemplo, temos: o processo de sucessão, a indicação de filhos em postos de gestão, os conflitos entre o fundador e filho que atua como CEO. A dinâmica familiar envolve uma série de entradas e saídas de pessoas: pelo casamento, nascimento, divórcio e morte. Por isso, ainda de acordo com Gersick et al. (2006), a maior parte das empresas começa com um único proprietário, depois passa pela sociedade entre irmãos em que alguns proprietários distribuem as ações para um consórcio de primos ou se limitam a uma sociedade entre irmãos na geração.

Sharma (2004) frisa que a literatura sobre empresas familiares está se desenvolvendo para compreender a natureza, causas e implicações dos diferentes tipos de conflitos relacionais existentes neste tipo de organização. Salienta, ainda, que alguns pontos fracos se tornam evidentes nessas instituições, os principais são: ausência de estratégias definidas em alguns casos e confusão entre propriedade e gestão.

\section{Governança corporativa e conselho de administração em empresas familiares}

A implementação de práticas de governança corporativa varia de acordo com a empresa. Boas práticas de governança corporativa podem gerar benefícios que estão centrados em obter maior harmonia entre os seus sócios e aumentar a eficiência na gestão através da contribuição de conselheiros externos (Santos \& Aragaki, 2015). Com base nesse contexto, a primeira hipótese de pesquisa foi estruturada.

Hipótese 1: Em empresas familiares, a participação feminina no conselho de administração tem relação com o desempenho financeiro

A boas práticas de governança corporativa contribuem para a criação de instrumentos que separam a propriedade e a gestão do negócio, pois pode ocorrer a sobreposição de papéis e funções nas empresas familiares. A adoção desses mecanismos é importante para que se evite a transferência de conflitos da família para a empresa. (Silva, 2017).

Em empresas familiares um fator crítico é a ausência de sucessores preparados para assumir a liderança da organização. Para evitar que isso ocorra, o conselho deve manter atualizado um Plano de Sucessão do DiretorPresidente e assegurar que este o faça para todas as pessoas chaves da organização (Santos \& Aragaki, 2015).

Dentre as razões que levam uma empresa familiar a implantar melhores mecanismos de governança corporativa e a ter um conselho de administração, mesmo que esteja preparada, é o desconhecimento dos assuntos essenciais para a continuidade da empresa. Por isso, é necessário que ela tenha um suporte de um CA diversificado para auxiliá-la e tenha conselheiros com experiência diversificada para proporcionar diretrizes de tal forma que a organização possa decidir com segurança (Silva, 2017). 
Darmadi (2013) afirma que o cenário da diversidade de gênero pode ensejar conflitos, mas também a construção de relações humanas favoráveis na obtenção no lucro contábil das empresas. Adams e Ferreira (2009) concluíram que a diversidade de gênero nos conselhos administrativos tem efeito significativo nas tomadas de decisões. Além disso, as mulheres têm papel importante nas posições relacionadas ao monitoramento nos conselhos administrativos e na gestão de riscos dessas empresas. Considerando esse contexto, a segunda hipótese de pesquisa foi estruturada.

Hipótese 2: Em empresas familiares, a participação feminina no conselho de administração tem relação com o risco da empresa.

\section{Metodologia}

A amostra usada para realização da pesquisa é composta somente por empresas listadas e negociadas na B3 (Bolsa de Valores de São Paulo). Do universo de 234 empresas, foram coletadas 218 empresas com o total de 6.088 observações, divididas em trimestres. Embora os dados de governança apresentem menor variância ao longo do período analisado, o estudo considerou dados financeiros trimestrais para poder explorar mais a dinâmica financeira e econômica da empresa ao longo do ano.

Dezesseis empresas foram excluídas da amostra por não apresentarem informações completas para o período analisado; e/ou com patrimônio líquido negativo; e/ou não constarem dados referentes à estrutura de propriedade; e/ou, ainda, não terem sido encontrados dados de composição do CA.

O foco deste trabalho é analisar o desempenho e risco financeiro em empresas familiares e a figura da mulher nos Conselhos de Administração, por essa razão os bancos e instituições financeiras não foram consideradas por terem estruturas muito distintas das empresas.

As informações sobre composição do Conselho de Administração foram consultadas nos Formulários de Referência disponíveis na base de dados da Comissão de Valores Imobiliários (CVM), especificamente na seção Estrutura Administrativa, presente na opção Informações Periódicas e Eventuais de Companhias. O Formulário de Referência (FRE) é considerado a principal fonte para consulta de dados sobre as empresas de capital aberto, que incluem: estrutura de controle, dados financeiros, políticas e descrição da composição do conselho.

A classificação quanto ao gênero se fez segundo experiência profissional e bibliografia da administração, expressa pelos pronomes pessoais, contida no capítulo 12 do FRE - Assembleia e Administração, subseção 12.5 - Composição e Experiência Profissional da Administração.

A estrutura de propriedade das empresas foi classificada em conformidade com as informações relativas ao acionista controlador e controle direto, também consultados nos Formulários de Referência - capítulo 15 - Controle e Grupo Econômico, subseção 15.1 - Posição Acionária. Esses dados foram utilizados para a criação da variável dummy família, que assume valor igual a 1(um) quando a estrutura de propriedade é familiar e 0 (zero) para os demais tipos de controle.

As informações sobre o gênero e da estrutura de propriedade foram coletadas manualmente em função das particularidades desta pesquisa, que exigiu, em alguns casos, identificação e interpretação dos dados reportados.

A dummy governança foi gerada para distinguir as empresas participantes de níveis mais elevados de governança corporativa. Esses elementos foram obtidos junto ao anuário de governança corporativa, apresentados na B3 (Bolsa de Valores de São Paulo). Ela assumiu valor igual a 1(um) para as empresas listadas nos níveis 2 ou Novo Mercado e 0 (zero), caso contrário.

No que se refere às informações contábeis e de risco foram extraídos da base da Economática®. Os valores contábeis foram divididos em trimestres, disponibilizados em reais e ao final de cada exercício social, permitiram 
capturar o ativo total, dívida total líquida e receita líquida. O logaritmo neperiano foi aplicado para atenuar valores extremos, pois a base de dados apresenta bastante heterogeneidade em diversos aspectos como, por exemplo, companhias de diversos setores, tamanhos ou com valores de mercado distintos.

A análise compreendeu-se do ano de 2010 a 2016. A escolha desse período decorreu-se da implementação do IFRS - International Financial Reporting Standards - ou, em português, Normas Internacionais de Informação Financeira.

\section{Especificações econométricas}

Neste trabalho, utilizou-se a metodologia de painel com efeitos aleatórios para observar a relação da diversidade de gênero nos conselhos de administração com o desempenho e risco financeiro nas empresas familiares.

Aplicou-se o Teste de Hausman para comparar a consistência dos efeitos fixos e efeitos aleatórios para maior robustez ao trabalho. Ambos os estimadores são consistentes, mas o estimador de efeitos aleatórios é mais adequado contra a hipótese alternativa de que o estimador de efeitos aleatórios é inconsistente e o estimador de efeitos fixos é consistente. Caso não se rejeite $\mathrm{H} 0$, opta-se pelo modelo de efeitos aleatórios, pois é assintoticamente mais eficiente ou apresenta menor variância (Wooldrige, 2010). Esse estudo adotou o estimador de efeitos aleatórios, porque as informações referentes à estrutura de controle familiar foram invariantes no tempo da amostra deste estudo. Com a utilização do método de efeitos fixos não seria possível observar a relação entre a variável dummy de controle familiar com as variáveis dependentes.

Adams, Hermalin e Weisback (2010) reconhecem que as análises empíricas sobre Conselho de Administração são difíceis, pois a maioria das variáveis de interesses são endógenas. A causalidade é quase impossível de determinar. As três principais causas de endogeneidade nas pesquisas em Finanças Corporativas são: variáveis omitidas, erros de mensuração e simultaneidade (Roberts \& Whited, 2012). Esse estudo não tem, porém, como objetivo realizar inferência causal entre as variáveis analisadas. Portanto, o objetivo do estudo é analisar as relações que possam existir entre essas variáveis.

O modelo econométrico estimado está representado nas Equações (1) e (2).

Desempenho da Firma ${ }_{i t}=\alpha_{1 i}+\beta_{1} \%$ Participação Feminina Fit $+\beta_{2}$ Família $_{i}+$

$\beta_{3}$ Família $_{i}{ }^{*}$ Participação Feminina ${ }_{\text {it }}+\theta_{1} Z_{\text {it }}+\varepsilon_{1 \text { it }}$

Risco $_{\text {it }}=\alpha_{2 i}{ }^{+} \quad \beta_{1} \%$ Participação Feminina $_{\text {it }}+\beta_{2}$ Família $_{\mathrm{i}}+$

$\beta_{3}$ Famíliai $^{*}$ ParticipaçãoFeminina ${ }_{\text {it }}+\theta_{1} Z_{\text {it }}+\varepsilon_{2 \text { it }}$

O Desempenho da empresa foi computado por meio de três métricas distintas: Return on Equity (ROE), Return on Assets (ROA) e Q de Tobin. Participação feminina é a razão entre o total de mulheres no conselho e o total de membros. Família é uma dummy que indica se a companhia $i$ possui controle familiar. $Z$ denota as variáveis de controle: ativo total (proxy do tamanho da organização $i$ ), alavancagem financeira (proxy do endividamento), crescimento das vendas (proxy de resultados futuros), dummy governança, dummies de trimestre para controlar tendências temporais e dummies de setores para controlar efeitos fixos de indústrias específicas.

Risco equivale ao desvio-padrão da volatilidade das ações negociadas em bolsa, bem como, todas as demais variáveis já referenciadas na Equação (1).

Criaram-se diferentes formas funcionais com a aplicação do logaritmo neperiano sobre as variáveis q-Tobin e Volatilidade. Entre as variáveis de mensuração de desempenho e risco financeiro, os indicadores empregados estão definidos na Tabela 2. A escolha dos índices financeiros e das variáveis de controle deu-se por serem os mais utilizados na literatura, como por exemplo, as especificações de Green e Homroy (2015). 
Tabela 2

\section{Variáveis de Desempenho e Risco Financeiro}

\begin{tabular}{ll}
\hline \multicolumn{1}{c}{ Variáveis } & \multicolumn{1}{c}{ Definição Operacional } \\
\hline $\begin{array}{l}\text { Medida de Desempenho } \\
\text { Return on Equity (ROE) }\end{array}$ & Lucro Líquido / Patrimônio Líquido \\
Return on Assets (ROA) & Lucro Operacional / Ativo Total \\
Q-Tobin & (Valor de Mercado + Dívida Total) / Ativo Total \\
Ln_Q-Tobin & Ln (Valor de Mercado + Dívida Total) / Ativo Total \\
Medida de Risco & \\
Volatilidade & Desvio-padrão do retorno das ações \\
Ln_Volatilidade & Ln (Desvio-padrão do retorno das ações) \\
\hline
\end{tabular}

Nota. Fonte: elaboração própria.

Destaca-se que a interação dos termos família*participação feminina é justamente a variável de interesse que denota o efeito da presença de mulheres em conselhos de empresas familiares.

As regressões recorreram-se às variáveis winsorizadas na ordem de 5\% para mitigar o efeito de observações extremas. Pela heterogeneidade de empresas na amostra coletada, espera-se que haja heterocedasticidade nos modelos. Para minimizar os problemas de heterocedasticidade, utilizaram-se os estimadores de erro-padrão robusto de White.

\section{Resultados}

\section{Estatística descritiva}

Os dados levantados das empresas apresentaram uma discrepância entre os assentos dos conselhos administrativos entre os gêneros. A Tabela 3 mostra que das 218 firmas pesquisadas, encontrou-se um total de 2.459 assentos, com uma média de 10,22 conselheiros por organização, com a presença de 9,43 homens e 0,79 mulheres. Desses assentos: 2.246 foram ocupados por homens e 213 por mulheres, que corresponderam a uma relação de $91,34 \%$ e $8,66 \%$, respectivamente. Tais dados revelaram que a presença da mulher nas corporações ainda é baixa.

O grupo de empresas familiares apresentou 3.840 observações, com uma média de 9,89 conselheiros por empresa, com 9,06 homens e 0,83 mulheres. Com relação às empresas não controladas por famílias, a amostra apresentou 80 empresas e 2.248 observações, essas apresentaram uma média de 10,78 conselheiros por companhia, superior em 0,90 ao grupo Família. A média de homens foi 10,06, maior em 1,00. A média de mulher foi 0,72, sendo inferior em 0,10 . 
Tabela 3

\section{Estatística Descritiva}

\begin{tabular}{|c|c|c|c|c|c|}
\hline \multicolumn{6}{|c|}{ Média } \\
\hline & Total & Família & Não Famílias & Diferença & Stat t \\
\hline \multicolumn{6}{|l|}{ Característica do Conselho } \\
\hline Tamanho do Conselho & 10,22 & 9,89 & 10,78 & $-0,90$ & $-6,19 * * *$ \\
\hline Número de Homens & 9,43 & 9,06 & 10,06 & $-1,00$ & $-7,46^{* * *}$ \\
\hline Número de Mulheres & 0,79 & 0,83 & 0,72 & 0,10 & $3,38 * * *$ \\
\hline \multicolumn{6}{|l|}{ Medidas de Desempenho } \\
\hline ROE (LL/PL) & 0,47 & 0,31 & 0,76 & $-0,45$ & $-1,51$ \\
\hline ROA (L. Oper. /AT) & 0,08 & 0,06 & 0,11 & $-0,05$ & $-1,87$ \\
\hline Q-Tobin ((VM + Div.) / AT) & 1,16 & 1,22 & 1,04 & 0,19 & 1,94 \\
\hline \multicolumn{6}{|l|}{ Medida de Risco } \\
\hline Volatilidade & 35,71 & 35,33 & 36,45 & $-1,13$ & $-1,23$ \\
\hline Número de Empresas & 218 & 138 & 80 & & \\
\hline Observações & 6.088 & 3.840 & 2.248 & & \\
\hline
\end{tabular}

Nota. Fonte: elaboração própria.

É importante destacar que a diferença da superioridade de mulheres conselheiras nas empresas familiares foi estatisticamente significante a $1 \%$, quando comparada às empresas controladas por grupos não constituídos de famílias. Pode-se afirmar com esses dados que as empresas de propriedade não familiar apresentaram um CA com mais membros e com menor número de mulheres.

As médias dos indicadores ROE e ROA foram numericamente superiores às apresentadas pelas empresas familiares, porém a estatística t não foi estatisticamente significante. Já o q-Tobin e a Volatilidade foram inferiores, mas também não foram estatisticamente significantes.

A Tabela 4 apresenta o número de empresas e mulheres no Conselho de Administração dividida pela estrutura de propriedade, conforme classificação apresentada pelo FRE. A estrutura de propriedade está dividida em: estatal, familiar, fundo de investimento, pessoa jurídica, estrangeiro, fundação e fundo de pensão.

Tabela 4

\section{Percentual de Firmas e Mulheres por Controle}

\begin{tabular}{|c|c|c|c|c|c|}
\hline Controle & $\mathrm{N}^{\mathrm{o}}$ Firmas & $(\%)$ & $\mathrm{N}^{\circ}$ Conselheiros & $\mathrm{N}^{\circ}$ Mulheres & $(\%)$ \\
\hline Estado & 5 & $2 \%$ & 86 & 6 & $7 \%$ \\
\hline Família & 138 & $63 \%$ & 1.508 & 143 & $9 \%$ \\
\hline Fundo de investimento & 15 & $7 \%$ & 155 & 8 & $5 \%$ \\
\hline Pessoa jurídica & 28 & $13 \%$ & 286 & 18 & $6 \%$ \\
\hline Estrangeiro & 24 & $11 \%$ & 296 & 27 & $9 \%$ \\
\hline Fundação & 2 & $1 \%$ & 25 & 4 & $16 \%$ \\
\hline Fundo de pensão & 6 & $3 \%$ & 103 & 7 & $7 \%$ \\
\hline Total & 218 & $100 \%$ & 2.459 & 213 & $8,66 \%$ \\
\hline
\end{tabular}

Nota. Fonte: elaboração própria. 
Dentre os sete tipos de estruturas de propriedade, as famílias concentraram o maior número de empresas, o equivalente a 138 (63\%). Desse total, o número de conselheiros foi de 1.508 e o de mulheres que ocuparam lugares no conselho é de 143 (9,48\%). Embora, o número de empresas classificadas como fundação seja pequeno, essas organizações apresentaram a maior representatividade feminina: $16 \%$ em seus conselhos de administração.

\section{Resultados multivariados}

Os resultados estimados encontram-se apresentados na Tabela 5.

Tabela 5

Efeitos Aleatórios e as Medidas de Desempenho e Risco

\begin{tabular}{|c|c|c|c|c|c|c|}
\hline \multirow[t]{2}{*}{ Medida de Desempenho e Risco } & \multicolumn{6}{|c|}{ Efeitos Aleatórios } \\
\hline & q-Tobin & $\begin{array}{l}\text { Ln_q- } \\
\text { Tobin }\end{array}$ & ROA & ROE & Volatilidade & Ln_Volatilidade \\
\hline \multirow[t]{2}{*}{ Participação de Mulheres } & $0,40 * *$ & $0,70 * * *$ & $-0,00$ & $-0,23 * *$ & 4,82 & 0,21 \\
\hline & $(2,15)$ & $(3,56)$ & $(-0,15)$ & $(-2,03)$ & $(0,41)$ & $(0,60)$ \\
\hline \multirow[t]{2}{*}{ Família } & $1,47 * * *$ & $0,64 * * *$ & $0,06^{*}$ & $-0,24$ & $-49,27 * * *$ & $-1,45^{* * *}$ \\
\hline & $(3,23)$ & $(3,56)$ & $(-1,85)$ & $(-1,40)$ & $(-2,92)$ & $(-2,88)$ \\
\hline \multirow[t]{2}{*}{ Família*Participação de Mulheres } & 0,12 & $-0,22$ & $-0,03$ & 0,21 & $28,98 * * *$ & $0,90 * *$ \\
\hline & $(0,49)$ & $(-0,89)$ & $(-0,15)$ & $(1,49)$ & $(2,07)$ & $(2,14)$ \\
\hline \multirow[t]{2}{*}{ Ln (Ativo Total) } & $-0,13 * * *$ & $-0,14 * * *$ & $-0,01 *$ & $-0,05 * * *$ & $-5,38 * * *$ & $-0,13 * * *$ \\
\hline & $(-4,80)$ & $(-4,98)$ & $(-1,71)$ & $(-4,07)$ & $(-5,00)$ & $(-3,91)$ \\
\hline \multirow[t]{2}{*}{ Família*Ln (Ativo Total) } & $-0,15 * * *$ & $-0,07 * *$ & $0,00 * * *$ & $0,01^{*}$ & $2,14 * *$ & 0,04 \\
\hline & $(-4,26)$ & $(-2,13)$ & $(3,09)$ & $(1,85)$ & $(1,96)$ & $(1,98)$ \\
\hline \multirow[t]{2}{*}{ Ln (Alavancagem) } & $0,09 * * *$ & $0,13 * * *$ & $0,00 * *$ & $0,01^{*}$ & $0,36^{* *}$ & $-0,01^{*}$ \\
\hline & $(6,82)$ & $(9,40)$ & $(2,45)$ & $(1,78)$ & $(2,58)$ & $(1,94)$ \\
\hline \multirow[t]{2}{*}{ Família* Ln (Alavancagem) } & $0,04 * *$ & $0,02 *$ & $-0,00 * * *$ & $0,01 * *$ & $1,40 * *$ & $0,07 * *$ \\
\hline & $(2,22)$ & $(1,73)$ & $(-2,89)$ & $(2,68)$ & $(2,46)$ & $(2,36)$ \\
\hline \multirow[t]{2}{*}{ Ln (Crescimento de Vendas) } & $-0,01$ & $-0,02 *$ & $-0,01 * * *$ & $-0,01 *$ & $-2,95 * * *$ & $-0,00 * *$ \\
\hline & $(-0,55)$ & $(-1,94)$ & $(-5,33)$ & $(-1,85)$ & $(-3,79)$ & $(-2,47)$ \\
\hline \multirow[t]{2}{*}{$\begin{array}{l}\text { Família* Ln (Crescimento de } \\
\text { Vendas) }\end{array}$} & 0,07 & $0,08 * * *$ & $0,01 * * *$ & $0,01 *$ & $-2,95 * * *$ & $-0,00 * *$ \\
\hline & $(1,55)$ & $(4,11)$ & $(2,83)$ & $(1,86)$ & $(1,92)$ & $(1,93)$ \\
\hline \multirow[t]{2}{*}{ Governança } & $0,38 * *$ & $0,38 * *$ & $0,01 *$ & $-0,02 *$ & $6,17 *$ & $0,19 *$ \\
\hline & $(2,02)$ & $(2,16)$ & $(1,72)$ & $(-1,74)$ & $(1,73)$ & $(1,77)$ \\
\hline \multirow[t]{2}{*}{ Família*Governança } & $0,13 * *$ & $0,10^{*}$ & $0,01 * *$ & $-0,01 * *$ & $-10,07 * *$ & $-0,28 * *$ \\
\hline & $(1,98)$ & $(1,99)$ & $(2,20)$ & $(-1,98)$ & $(-2,26)$ & $(-2,08)$ \\
\hline \multirow[t]{2}{*}{ Constante } & $1,75^{* * *}$ & 0,04 & $0,13 * * *$ & $0,73 * * *$ & $99,30 * * *$ & $5,04 * * *$ \\
\hline & $(4,40)$ & $(0,11)$ & $(4,69)$ & $(5,12)$ & $(7,45)$ & $(12,68)$ \\
\hline
\end{tabular}




\section{Tabela 5 (continuação)}

\begin{tabular}{lcccccc}
\hline Medida de Desempenho e Risco & \multicolumn{7}{c}{ Efeitos Aleatórios } \\
\cline { 2 - 7 } & q-Tobin & $\begin{array}{c}\text { Ln_q- } \\
\text { Tobin }\end{array}$ & ROA & ROE & Volatilidade & Ln_Volatilidade \\
\hline Dummy Tempo & Sim & Sim & Sim & Sim & Sim & Sim \\
Dummy Setor & Sim & Sim & Sim & Sim & Sim & Sim \\
Winsor (5\%) & Sim & Sim & Sim & Sim & Sim & Sim \\
Teste de Hausman & 0,98 & 0,99 & 0,00 & 0,76 & 0,98 & 1,00 \\
Observações & 3.510 & 3.510 & 3.512 & 3.363 & 2.260 & 2.260 \\
$\mathrm{R}^{2}$ & 0,20 & 0,24 & 0,34 & 0,11 & 0,12 & 0,12 \\
\hline
\end{tabular}

Nota. Fonte: elaboração própria.

As estatísticas de teste t encontram-se entre parênteses e *,**,*** são notações para indicar significância estatística a $10 \%, 5 \%$ e $1 \%$, respectivamente

Os resultados evidenciam uma relação negativa entre participação feminina nos conselhos de administração e o índice de rentabilidade ROE. O resultado para a relação entre a participação feminina e o Q de Tobin (proxy para geração de valor) foi positiva. Ao considerar como variável de interesse a Volatilidade, o resultado foi negativo e estatisticamente significante. Esses resultados evidenciados na Tabela 5 nos informaram que empresas com menores índices de volatilidade refletem menores riscos e empresas que apresentam maiores Q de Tobin registram maiores valor de mercado. O que essa pesquisa evidenciou foi que a presença da diversidade de gênero nos conselhos é positiva.

A dummy família apresentou uma relação negativa com as Volatilidade e ROE e positiva para os indicadores $\mathrm{Q}$ de Tobin e ROA. Os coeficientes foram estatisticamente significantes a 5\% e 10\%, exceto o ROE. Esse fato indicou que as organizações familiares apresentam em média rentabilidade e risco inferiores. Com relação ao risco, as empresas com menor volatilidade em seus resultados deveriam ser menos propensas a dificuldades financeiras, o que pode tornar o custo do endividamento mais barato (Aharon \& Yagil, 2019).

A variável de interação Família*Participação Feminina permite analisar se o impacto da participação feminina é diferente nas empresas controladas por famílias. Esse efeito foi positivo para os índices q-Tobin, ROE e Volatilidade e negativo para o ROA. No entanto, somente a variável Volatilidade demonstrou significância estatística.

Com relação às variáveis de controle, todas foram estatisticamente significantes a 5\%, exceto na equação de Q de Tobin, na coluna 2. As variáveis de controle interagidas com a dummy família apresentaram resultados similares aos já citados anteriormente. Todas foram estatisticamente significantes, com exceção de Crescimento de Vendas no modelo Q de Tobin. Encontrou-se um resultado consistente da relação entre diversidade de gênero no conselho de administração e as quatro medidas de desempenho e risco financeiro.

De acordo com os modelos utilizados: ROA e Volatilidade, os coeficientes de diversidade obtidos não foram estatisticamente significantes. Tal fato indica que não é possível estabelecer uma relação entre desempenho e risco financeiro da empresa com a participação de mulheres no conselho para essas variáveis. Esse resultado está em linha com as conclusões dos estudos de Campbell e Mínguez-Vera (2008) e de Silva e Martins (2015).

A variável de desempenho, medida pelo $\mathrm{Q}$ de Tobin, encontrou uma relação positiva e estatisticamente significante entre a diversidade de gênero e geração de valor para empresa. No que se refere a esse índice, empresas com maior participação de mulheres no CA apresentam, em média, valor maior. Esse resultado é similar ao encontrado por Carter, Simkins e Simpson (2002). De toda forma, Adams e Ferreira (2009) encontraram evidências de que a relação entre diversidade de gênero e a performance financeira não é conclusiva. 
A diferença desses resultados pode ser explicada pelo fato dessas variáveis não serem similares em sua natureza e, por conseguinte, não conterem a mesma informação financeira. Enquanto ROE e ROA são métricas que refletem o retorno contábil gerado para os acionistas, o Q de Tobin representa uma métrica baseada nas expectativas de mercado, ou seja, na percepção da oportunidade de investimento a partir da previsão do fluxo de caixa futuro (Adams \& Ferreira, 2019).

Com relação às variáveis de controle, ativo total apresentou uma relação negativa e estatisticamente significante com o Q de Tobin, ou seja, quanto maior a empresa, menor o seu desempenho. No caso da alavancagem, a relação foi positiva e estatisticamente significante para todos os modelos, exceto ln_volatilidade. Isso indica que quanto maior o nível de endividamento das empresas, melhor sua performance. A relação da variável de crescimento das vendas com as variáveis dependentes de desempenho foi negativa e estaticamente significante para todos os modelos, exceto para a variável Q de Tobin.

A dummy de governança, tratada como variável de controle nesse estudo, foi positiva e estatisticamente significante em todos os modelos, com exceção da variável ROE. Nas empresas com controle familiar, a relação é estatisticamente significante em todas as equações, porém para as variáveis ROE e Volatilidade o sinal foi negativo.

Adams e Ferreira (2009) também afirmam que a relação entre diversidade de gênero e desempenho financeiro nas empresas parece ser mais complexa. Os resultados apresentados por eles demonstram que a diversidade tem um impacto positivo sobre as empresas que apresentam uma governança mais fraca. Nas firmas com uma governança forte, o resultado pode ser o contrário. Reforçam, ainda, que a presença feminina tem um impacto relevante na estrutura dos conselhos, porém essas evidências não suportam políticas de cotas e/ou instrumentos normativos. Essas propostas devem ser motivadas por outros argumentos diferentes de melhoras na governança corporativa e desempenho financeiro das empresas.

A interação entre dummy família e participação feminina, no modelo de Volatilidade, demonstrou uma relação positiva e estatisticamente significante entre a participação feminina e o risco da empresa em empresas com controle familiar. Esse resultado permite inferir que a volatilidade é mais afetada pela participação feminina nas empresas familiares do que as de controle não familiar.

No caso do ROA, as variáveis participação feminina e a interação entre controle familiar e participação feminina não apresentaram significância estatística. Esse fato nos permite inferir que a presença da mulher não apresenta nesse estudo relação estatisticamente significante com o ROA. Porém, pode-se considerar que as empresas controladas por famílias têm, em média, o ROA maior do que o outro grupo.

Embora a proporção de mulheres nos CA seja pequena, é possível estabelecer relações quando se considera além das características quantitativas, as qualitativas, como a estrutura de controle das empresas e as relações organizacionais. Os resultados encontrados vão de encontro com a hipótese 1 desse estudo que procura analisar se em empresas familiares, a participação feminina no conselho de administração tem relação com o desempenho financeiro. Os principais resultados mostram que não há evidências que haja essa relação em empresas familiares, porém pode-se inferir que a relação entre a participação das mulheres no CA e desempenho das empresas é estatisticamente significante independente da sua estrutura de controle. Por fim, quanto a segunda hipótese, os resultados evidenciam que em empresas familiares, a participação feminina no conselho de administração tem relação positiva com o risco da empresa, embora não haja a mesma relação ao analisar apenas a variável participação das mulheres no CA e sua relação com volatilidade das empresas.

\section{Limitações de Pesquisa}

As pesquisas que estudam assuntos relacionados a Conselhos de Administração e Finanças podem ser afetadas por problemas de endogeneidade. Apesar dos procedimentos de mitigação adotados, não se pode garantir a eliminação desses efeitos. Roberts e Whited (2012) sugerem que somente com instrumentos controlados é 
possível garantir que os problemas de endogeneidade sejam minimizados para assegurar inferências causais consistentes.

Uma outra possível limitação decorre de possíveis erros de mensuração das variáveis, pois a coleta de dados é realizada manualmente e nem sempre numa mesma temporalidade. A correta mensuração depende da qualidade e atualização dos dados disponibilizados pelas empresas, como por exemplo, o preenchimento incorreto do FRE (Formulário de Referência) da CVM pela empresa pode provocar distorção nas variáveis de diversidade e de estrutura de propriedade.

\section{Considerações Finais}

Embora a representatividade feminina nos conselhos corporativos continue a ser um tema central, ainda não existe um consenso com relação aos benefícios econômicos e financeiros que tais reformas possam trazer. A literatura, ainda, não fornece elementos conclusivos sobre o impacto da diversidade nos conselhos sobre as tomadas de decisões, que possam afetar positivamente os resultados financeiros e riscos das empresas.

As empresas sofrem uma crescente pressão popular para abraçar uma maior diversidade de gênero nos conselhos de administração. Apesar de não existir política de cotas no Brasil, como em outros países, por exemplo: Noruega, Dinamarca, Finlândia, movimentos e iniciativas de agentes internos e externos das empresas já induzem a nomeação de mais mulheres para o cargo de conselheira.

Nesse contexto, o presente estudo procurou avaliar se empresas, com maior diversidade de gênero em seus conselhos de administração, possuem resultados econômico-financeiros melhores. O estudo também procurou analisar se tal advento também se reflete na gestão de riscos dessas organizações no contexto de empresas familiares.

Os resultados encontrados evidenciam uma relação positiva da participação feminina no conselho com a geração de valor, utilizando como variável proxy o Q de Tobin. Esse efeito é menor nas empresas de controle familiar. Os resultados não permitiram encontrar efeitos sobre o ROA e ROE da participação feminina nos CAs. A presença de mulheres no CA de empresas controladas por famílias tem um impacto positivo sobre o risco. Já nas empresas não familiares, não se observam tais efeitos. Os indicadores: ROA, ROE e Volatilidade foram em média inferiores nas empresas controladas por famílias, já o Q de Tobin foi, em média, superior.

Por ser um tema novo e pouco explorado há oportunidades de pesquisa nos aspectos relacionados à nomeação de conselheiros em função dos objetivos e estratégias das empresas; ao direcionamento das ações das empresas de acordo com os estudos estatísticos, que elas revelem durante o processo de projeção de resultados; à constituição do conselho em função das necessidades e expectativas das empresas.

Apesar das poucas evidências empíricas sobre o tema, a diversidade de gênero nos conselhos de administração é recomendável e tal questão se baseia em senso de justiça, em vez de uma questão puramente econômica.

\section{Referências}

Adams, R. B., \& Ferreira, D. (2007). A theory of friendly board. The Journal of Finance, 62(1), 217-250. https://doi.org/10.1111/j.1540-6261.2007.01206.x

Adams, R. B., \& Ferreira, D. (2009). Women in the boardroom and their impact on governance and performance. Journal of Financial Economics, 94(2), 291-309. https://doi.org/10.1016/j.jfineco.2008.10.007 
Adams, R. B., Hermalin, B. E., \& Weisbach, M. S. (2010). The role of boards of directors in corporate governance: A conceptual framework and survey. Journal of Economic Literature, 48(1), 58-107. https://doi.org/10.1257/jel.48.1.58

Aharon, D. Y., \& Yagil, Y. (2019). The impact of financial leverage on the variance of stock returns. International Journal of Financial Studies, 7(1), 14. https://doi.org/10.3390/ijfs7010014

Álvares, E., Giacometti, C., \& Gusso, E. (2008). Governança corporativa: Um modelo brasileiro. Rio de Janeiro, RJ: Ed. Elsevier.

Barber, B. M., \& Odean, T. (2001). Boys will be boys: Gender, overconfidence, and common stock investment. Quarterly Journal of Economics, 116(1), 261-292. https://doi.org/10.1162/003355301556400

Bruni, A., Gherardi, S., \& Poggio, B. (2004). Entrepreneurmentality, gender and the study of women entrepreneurs. Journal of Organizational Change Management, 17(3), 256-268. http://dx.doi.org/10.1108/09534810410538315

Campbell, K., \& Mínguez-Vera, A. (2008). Gender diversity in the boardroom and firm financial performance. Journal of Business Ethics, 83(3), 435-451. https://doi.org/10.1007/s10551-007-9630-y

Carter, D. A., Simkins, B. J., \& Simpson, W. G. (2002, March). Corporate governance, board diversity, and firm value [Working Paper]. Oklahoma State University, Stillwater, OK, USA. Retrieved from https://ssrn.com/abstract=304499

Darmadi, S. (2013). Do women in top management affect firm performance? Evidence from Indonesia. Corporate Governance, 13(3), 288-304. https://doi.org/10.1108/cg-12-2010-0096

Daspit, J. J., Holt, D. T., Chrisman, J. J., \& Long, R. G. (2016). Examining family firm succession from a social exchange perspective: A multiphase, multistakeholder review. Family Business Review, 29(1), 44-64. http://dx.doi.org/10.1177/0894486515599688

Fama, E. F., \& Jensen, M. C. (1983). Separation of ownership and control. Journal of Law and Economics, 26(2), 301-325. Retrieved from www.jstor.org/stable/725104.

Ferreira, T. M., Cunha, J. S., \& Almeida-Santos, P. S. (2015, novembro). Diversidade de gênero v.s. Governança corporativa: Análise empírica entre as maiores cia. de capital aberto do Brasil. Anais do Congresso UnB de Contabilidade e Governança, Brasília, DF, 1.

Gersick, K. E., Davis, J. A., Hampton, M. M., \& Lansberg, I. (2006). De geração para geração. Rio de Janeiro: Elsevier.

Green, C. P., \& Homroy, S. (2015). Female directors, key committees, and firm performance [Economics Working Paper Series]. Lancaster University Management School, The Department of Economics, Lancaster, UK.

Grzybovsk, D., Boscarin, R., \& Migott, A. M. B. (2002). Estilo feminino de gestão em empresas familiares gaúchas. Revista de Administração Contemporânea, 6(2), 185-207. https://doi.org/10.1590/S141565552002000200011

Instituto Brasileiro de Governança Corporativa. (2015). Código das melhores práticas de governança corporativa. São Paulo: Autor. Recuperado de http://www.ibgc.org.br/userfiles/files/2014/files/codigoMP_5edicao_baixa.pdf

Instituto Brasileiro de Governança Corporativa. (2016). Perfil dos Conselhos de Administração. Recuperado de http://www.ibgc.org.br/userfiles/2014/files/Pesquisa_Perfil_Conselhos_2016_vfinal.pdf 
Jaskiewicz, P., \& Klein, S. (2007). The impact of goal alignment on board composition and board size in family businesses. Journal of Business Research, 60(10), 1080-1089. http://dx.doi.org/10.1016/j.jbusres.2006.12.015

Jensen, M., \& Meckling, W. (1976, October). Theory of the firm: Managerial behavior, agency costs and ownership structure. Journal of Financial Economics, 3(4), 305-360. https://doi.org/10.1016/0304$405 x(76) 90026-x$

Kabbach de Castro, L. R., Aguilera, R., \& Crespi, R. (2017). Family firms and compliance: Reconciling the conflicting predictions within the socioemotional wealth perspective. Family Business Review, 30(2), 137159. http://dx.doi.org/10.1177/0894486516685239.

Naldi, L., Chirico, F., Kellermanns, F. W., \& Camponiano, G. (2015). All in the family? An exploratory study of family member advisors and firm performance. Family Business Review, 28(3), 228-242. https://doi.org/10.1177/0894486515581951

Macêdo, K. B. (2001). Empresa familiar brasileira: Poder, cultura e decisão. Goiânia: Terra.

Monks, R. A. G., \& Minow, N. (2011). Corporate governance (5th ed.). West Sussex: John Wiley \& Sons.

Nisiyama, E. K. (2016). Diversidade do conselho de administração e a estrutura do capital (Tese de doutorado). Universidade Presbiteriana Mackenzie, São Paulo, SP, Brasil.

Projeto de Lei do Senado n. 112. (2010). Define percentual mínimo de participação de mulheres nos conselhos de administração das empresas públicas e sociedades de economia mista, suas subsidiárias e controladas e demais empresas em que a União, direta ou indiretamente, detenha a maioria do capital social com direito a voto. Recuperado de https://www25.senado.leg.br/web/atividade/materias/-/materia/96597

Roberts, M. R., \& Whited, T. M. (2012, outubro 5). Endogeneity in empirical corporate finance [Simon School Working Paper No. FR 11-29]. Simon Business School, University of Rochester, Rochester, NY, USA. http://dx.doi.org/10.2139/ssrn.1748604

Santos, A. C., \& Aragaki, C. (2015). A importância do conselho de administração em empresas familiares de capital fechado. Revista Eletrônica do Departamento de Ciências Contábeis \& Departamento de Atuária e Métodos Quantitativos da FEA-PUC/SP, 2(1), 65-85. Recuperado de https://revistas.pucsp.br/redeca/article/view/27900/19657

Sharma, P. (2004). An overview of the field of family business studies: Current status and directions for the future. Family Business Review, 17(1), 1-36. https://doi.org/10.1111/j.1741-6248.2004.00001.x

Sila, V., Gonzales, A., \& Hagendorff, J. (2016). Women on boardroom gender diversity affect firm risk? Journal of Corporate Finance, 36, 26-53. https://doi.org/10.1016/j.jcorpfin.2015.10.003

Silva, C. C. (2017). Governança corporativa em empresas de controle familiar: Compreendendo a dinâmica do conselho de família (Dissertação de mestrado). Universidade de São Paulo, São Paulo, SP, Brasil.

Silva, C. P. J., \& Martins, O. S. (2015). Mulheres no conselho afetam o desempenho financeiro? Uma análise da representação feminina nas empresas listadas no BM\&FBOVESPA. Anais do Congresso USP de Controladoria e Contabilidade, São Paulo, SP, Brasil, 15.

Silveira, A. M. (2004). Governança corporativa e estrutura de propriedade: Determinantes e relação com o desempenho das empresas no Brasil (Tese de doutorado). Departamento de Administração, Faculdade de Economia, Administração e Contabilidade, Universidade de São Paulo, São Paulo, SP, Brasil.

Steinberg, H., \& Blumenthal, J. (2011). A família empresária: Organizando as relações de afeto, poder e dinheiro por meio da governança corporativa. São Paulo: Editora Gente. 
Vidigal, A. C. (1996). Viva a empresa familiar! Rio de Janeiro: Rocco.

Wooldrige, J. M. (2010) Introductory econometrics: A modern approach. Ohio: South-Western.

\section{Autores}

Lilian Costa

Rua Itapeva, 474, Bela Vista, 01332-000, São Paulo, SP, Brasil

E-mail: lilian.costa1980@ gmail.com

(D) https://orcid.org/0000-0001-6360-6366

Joelson de Oliveira Sampaio

Rua Itapeva, 474, Bela Vista, 01332-000, São Paulo, SP, Brasil

E-mail: joelson.sampaio@fgv.br

(iD) http://orcid.org/0000-0001-6560-2481

Eduardo Silva Flores

Av. Professor Luciano Gualberto, 908, 05508-010, São Paulo, SP, Brasil

E-mail: eduardoflores@usp.br

(D) https://orcid.org/0000-0002-5284-5107

\section{Contribuições}

$1^{\circ}$ autor: levantamento, definição de metodologia e pesquisa.

$2^{\circ}$ autor: levantamento, definição de metodologia e pesquisa.

$3^{\text {o }}$ autor: levantamento, definição de metodologia e pesquisa.

\section{Financiamento}

Os autores informaram que não há existência de apoio financeiro para a pesquisa neste artigo.

\section{Conflito de Interesses}

Os autores informaram que não há conflito de interesses.

\section{Verificação de Plágio}

A RAC mantém a prática de submeter todos os documentos aprovados para publicação à verificação de plágio, mediante o emprego de ferramentas específicas, e.g.: iThenticate.

\section{Material Suplementar}

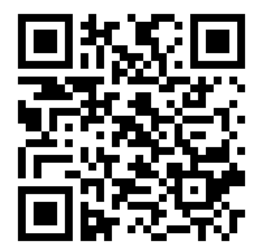

Todos os dados e materiais foram disponibilizados publicamente por meio da plataforma Zenodo e podem ser acessados em: Costa, Flores, \& Sampaio. (2019). Replication Data for: Diversidade de Gênero nos Conselhos de Administração e sua Relação com Desempenho e Risco Financeiro nas Empresas Familiares. Published by Journal of Contemporary Administration, 23(6), 2019. [Data set]. Journal of Contemporary Administration (RAC). Zenodo. http://doi.org/10.5281/zenodo.3445050 